Piotr Werner

\title{
A FEW REMARKS ON THE INTERPRETATION OF UHORCZAK'S TYPOGRAMS \\ AS TOOL FOR PRESENTATION AND TYPOLOGY OF MULTI-ROLE PHENOMENA
}

The typograms of F. Uhorczak (1972) are used to present the structural phenomena characterized by more than two features as the cartographical diagrams on the maps and as the tool for obtaining the typology of the objects. The method was extensively used in the 1970s in Polish cartography. It is similar to the Taylor's econograph, but has been modified by Uhorczak and applied in cartography. These phenomena presented are usually given as the structured whole objects (for example: demographical structure of the population according to regions). Each of the characteristics is given a share in terms of a percentage. The foundations of the method were described and discussed many times in the past (Uhorczak, Ostrowski 1972, Ratajski, 1989), but the typograms were used very rarely. The structure of a phenomenon is usually presented by the methods like structural circle diagrams and the typology is obtained using the statistical computer software. On the other side, the main reason might be the lack of knowledge of the method. There exist however some critical opinions concerning the fact, that the Uhorczak's typogram is not able to strictly define the type (Szewczuk 1987). The main criticisms concentrated on the fact that the method is not expressed mathematically and there is only graphical diagram, which is completely derived from the typology. Human eyes remain the only tools for comparing the shapes of two, three or more diagrams as representing the group with similar characteristics.

One of the advantages of the typogram is that its shape is geometric figure and is very easily recognized and understood. The main criticism concentrated on the fact that the typogram is not graph but diagram with many parameters. It was supposed that it is not illustration of the mathematical function. It was treated as artificial graphical diagram with very weak ability the characteristics of the structured phenomenon in the regions (Szewczuk,1987). Fig. 1 presents each of the aspects of the Uhorczak's typogram construction.

The proposed interpretation of maps containing Uhorczak's typograms (called cartotypograms by the author) not change the construction of diagram 


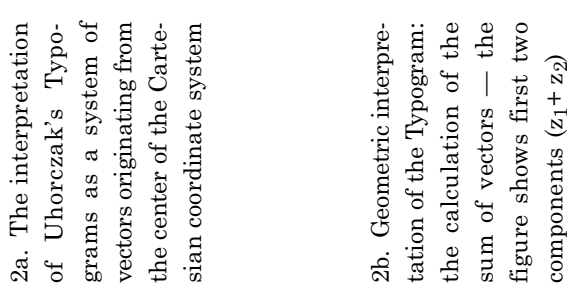

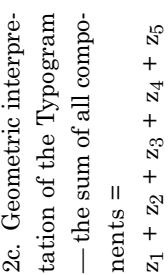

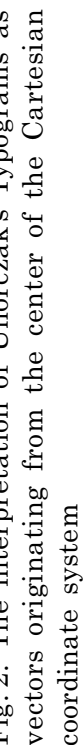

ก
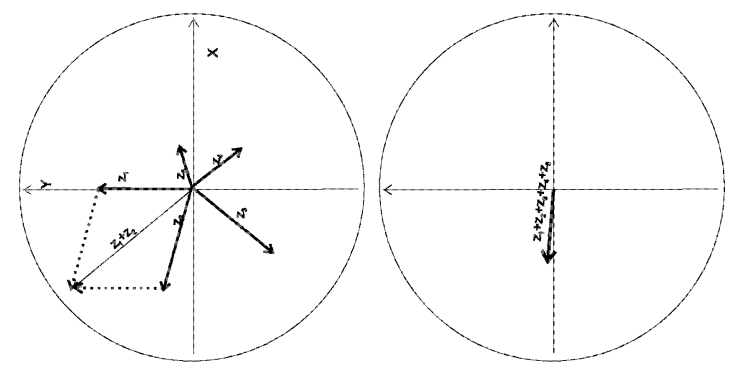

$\stackrel{\sim}{N}$

๙

ล
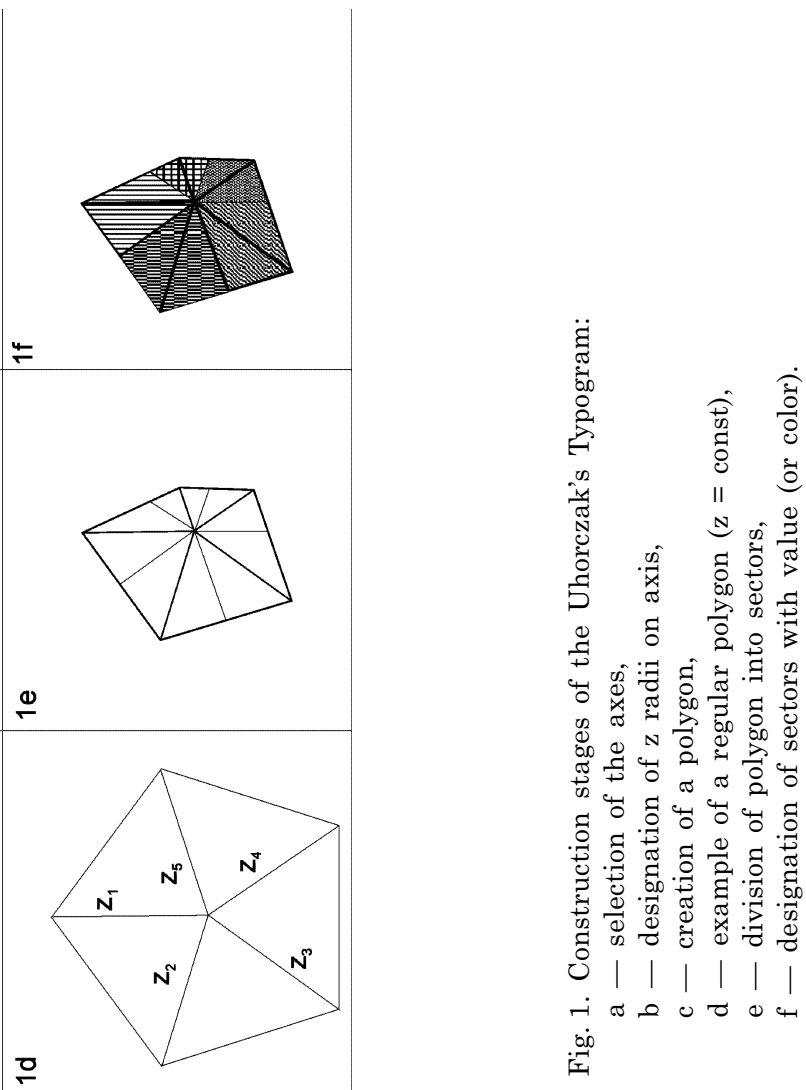
and its geometry. It is only the mathematical interpretation. Let us another look the problem and the formulation of the function. There is nothing against the treatment of the main axes of the single Uhorczak typogram as the vectors hooked at the one point (Fig. 2) in the center of the Cartesian coordinates on the plane. The proportions of the characteristics are retained. The vectors are scaled to cover the whole phenomenon. The typogram is contained within a circle. Its radius is equal 1 . If we sum the all vectors the mathematical expression of the typogram is as follows:

$$
\mathrm{T}=\sum_{i=1}^{n} \boldsymbol{r}_{i} \mathrm{e}^{j \frac{2 \pi}{\mathrm{n}} \mathrm{i}}
$$

(Equation 1)

where

$n$ - the number of the axes - the characteristics of the typogram; $n>2$ (in the data table it is the number of columns)

$r_{i}$ - the value of the share for the given characteristics

$i=1,2,3,4, \ldots$

$j$ - the sign of the imagine part of the complex number

$T-$ the vector of the sum (representing the determined shape of the typogram)

In the mathematical sense, each vector is a complex number. If we treat the length of the vector as the module of the complex number then we can present it the Euler formula: $r_{i} e^{j \varphi}$ with the angle equal $(2 * \Pi / n) * i$.

The Uhorczak's typogram displayed on the plane contains more than two characteristics (more than two axes) and the vectors constitute the dependent linear combination. Equation (1) usually remains unresolved. On the other hand the function is monotonic in its domain $<0,1>$ and it is possible to apply „brute force" and use computer to calculate the values of the function and display as a graph (Figs. 3,4,5,6,7). Here however, we used modified formula to obtain the rotation of the graphs. The angle of rotation was 90 degrees because the first axis of the graph should be in the same direction as the Y axis:

$$
\mathrm{T}=\sum_{i=1}^{n} \boldsymbol{r}_{i} \mathrm{e}^{j\left(\frac{2 \pi}{\mathrm{n}}\right) \mathrm{i}+\left(\frac{\pi-2 \pi}{2 \mathrm{n}}\right)}
$$

(Equation 2)

There are only points displayed on the graphs because another interpretation of complex numbers are the points on the plane. Each one marks the end of the vector sum and simultaneously represents the strictly defined shape of the Uhorczak's typogram (for the constant number of the characteristics). There are five graphs calculated and drawn: triangle, square, pentagon, hexagon and septangle. The arguments of the graphs were five ranges containing integer numbers, covering all the domain of $<0,100\rangle$. The only constraint was that the sum of the elements should be equal 100 . 


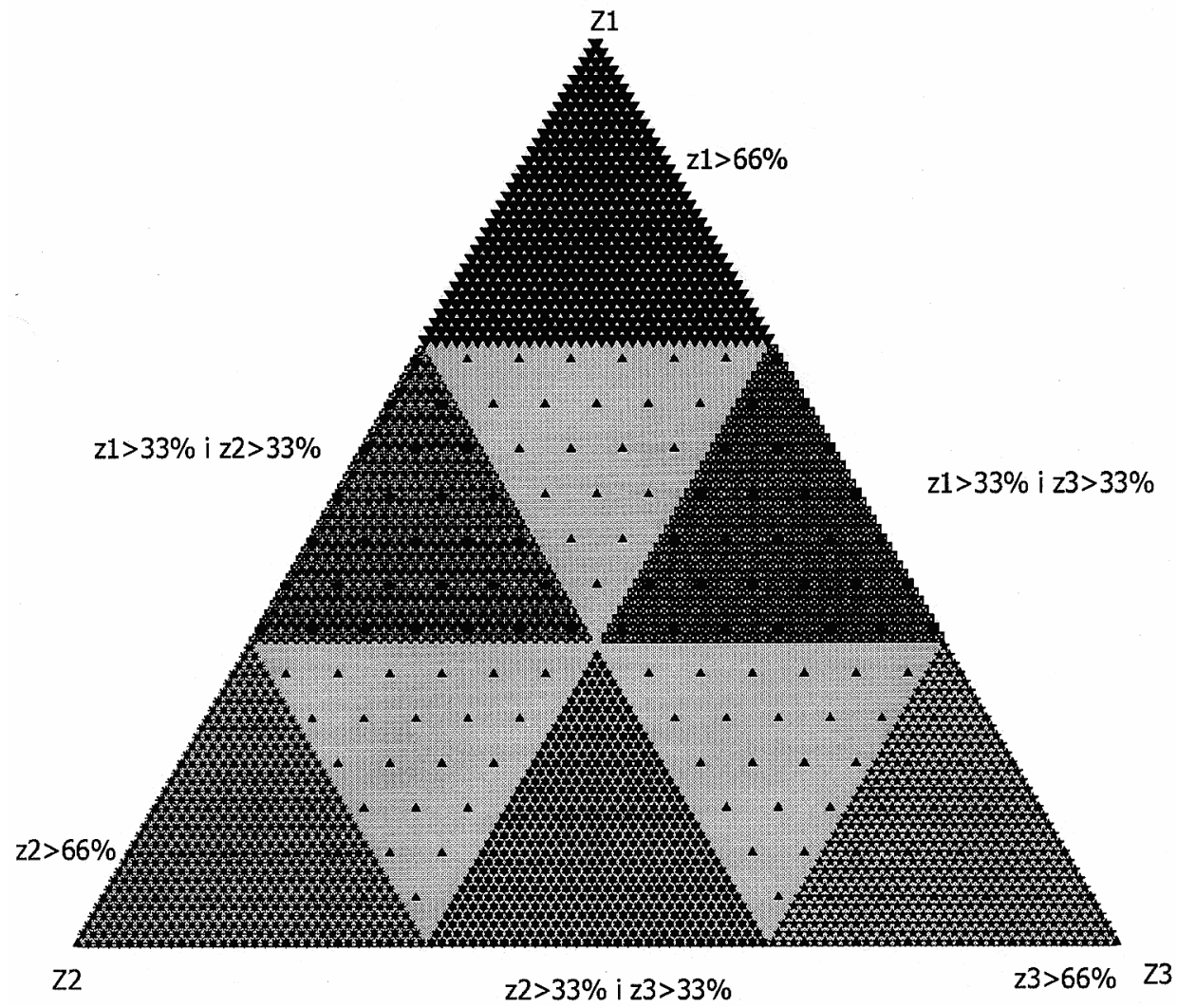

Fig. 3. A diagram of functions of the triangular vector typogram. Each point on the diagram represents a unique shape of a Uhorczak's Typogram. Points have been classed according the dominant feature (one or more). The similarity to the Ossan's Triangle is evident.

There were 5151 three-element combinations (with step equal to 1) for the triangle, 1771 - four-element ones (square, step = 5), $1001-$ for pentagon (step $=10), 3003-$ for hexagon $($ step $=10)$ and $8008-$ sevenelements combinations (step 10) for septangle. The final graphs are regular. The rules of the interpretation are the following: if the point lies near the center of the graph then the shape of Uhorczak's typogram is more regular. The interpretation of the triangle is that each point represents only the one shape of typogram. For the bigger number of the axes this rule is not obvious. The advantage of the graphs is the possibility to present data from different periods. The proposed name for the final graph is vector typogram (Werner, 1997)

The typogram's method is valuable tool for the typology and its cartographical presentation. 

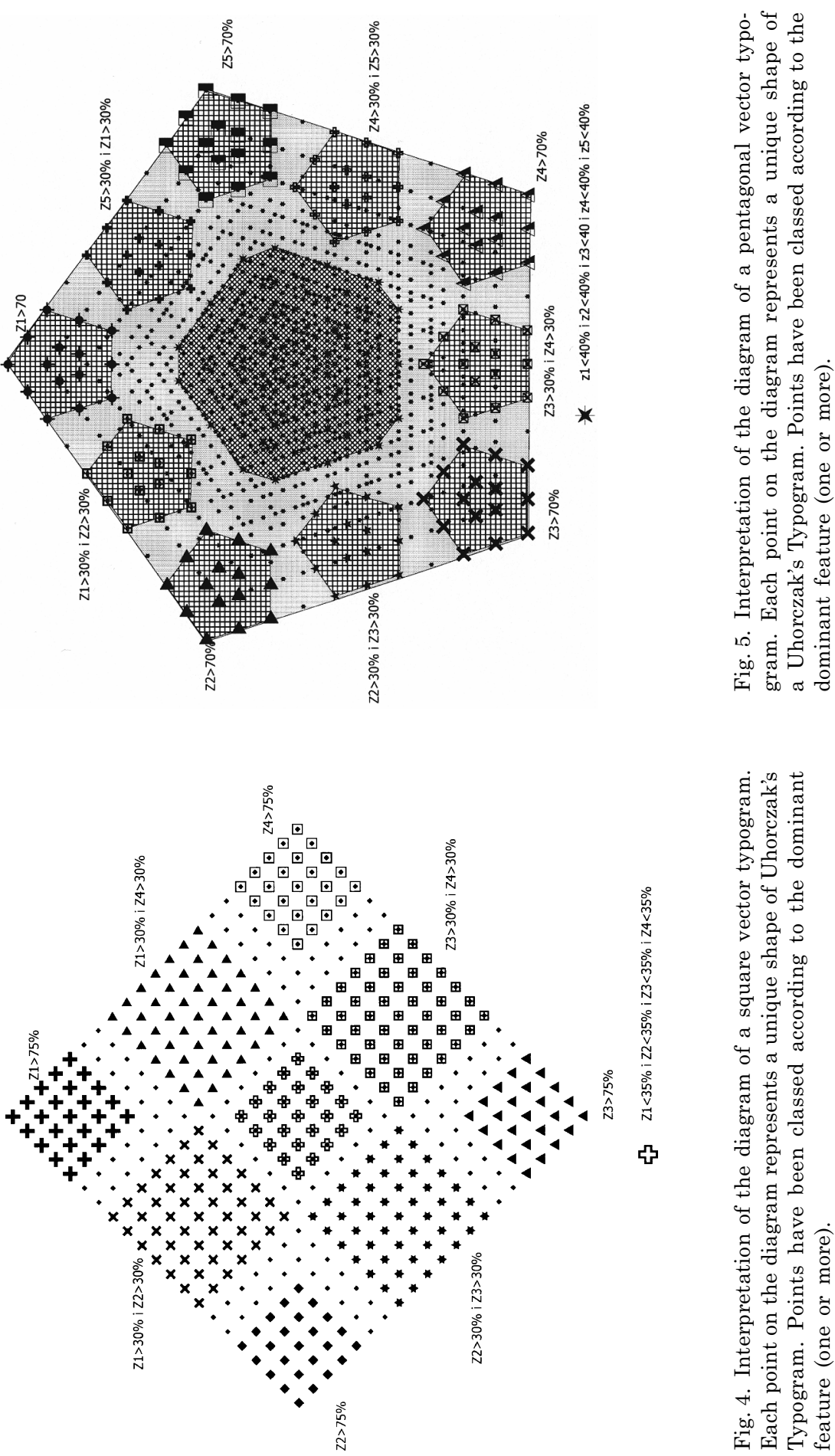

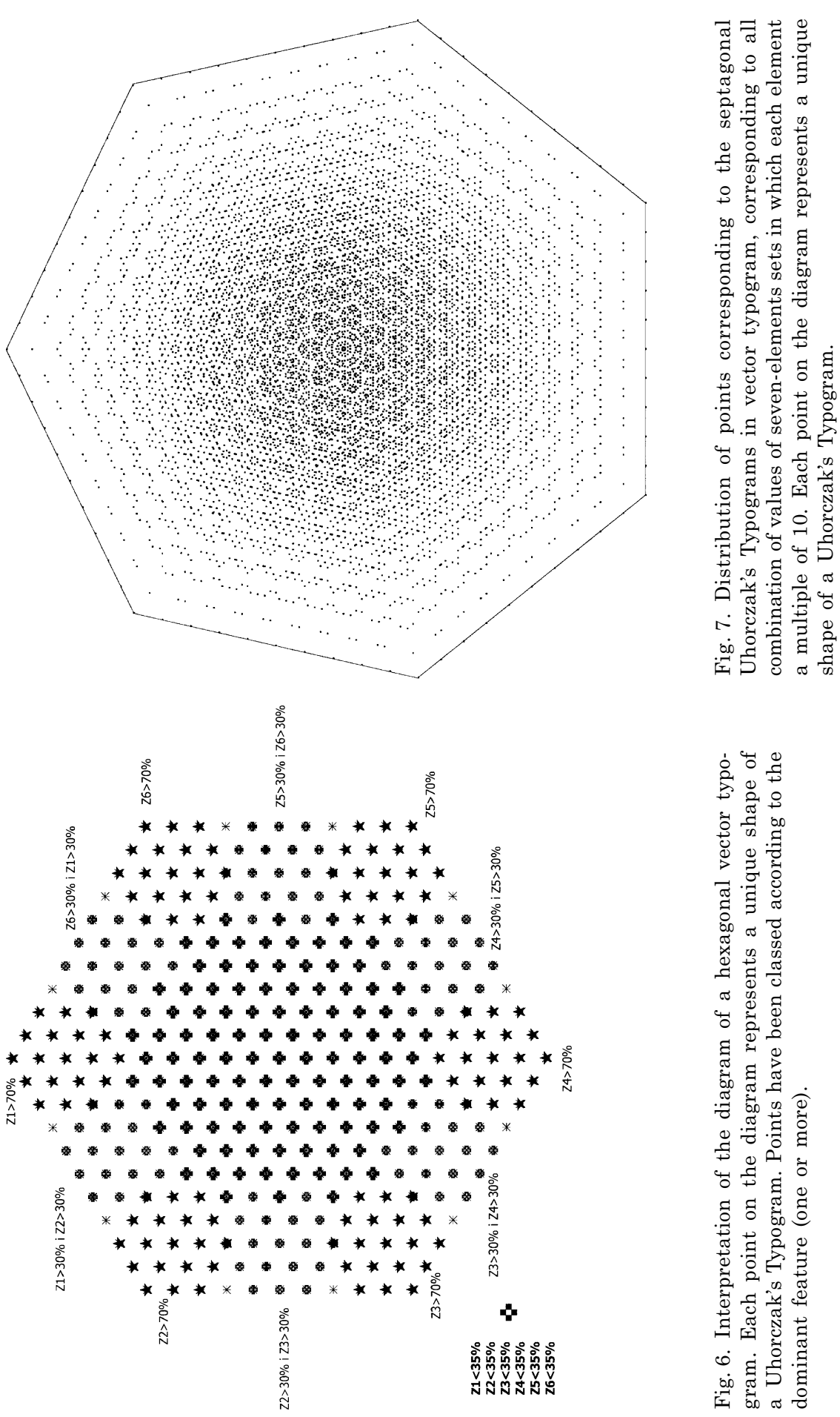


\section{REFERENCES}

Ratajski L., 1989, Metodologia kartografii spoteczno-ekonomicznej [Methodology of socioeconomic cartography; in Polish], Warszawa, PPWK.

S zewczuk J., 1987, Analiza metodyczna typogramu F. Uhorczaka [Methodological analysis of the Uhorczak's typogram; in Polish], Polski Przeglad Kartograficzny, 19 (4), 157-168.

Uhorczak F., Ostrowski J., 1972, Typogramy F. Uhorczaka jako środek graficznej prezentacji zjawisk wielocechowych [The typogram of F. Uhorczak as the means of graphical presentation of the multiattribute phenomena; in Polish], Polski Przeglad Kartograficzny, 4 (4), $145-150$.

Werner P., 1997, Zmiany struktur systemów energetycznych państw Unii Europejskiej $w$ latach 1979-1992 [Changes in the structures of the energy systems of the European Union countries in 1979-1992; in Polish], Warszawa, WGiSR UW. 